\title{
Working in old age in Mexico: implications for cognitive functioning
}

\author{
Francisca S. Rodriguez ${ }^{1,2,3 *}$ (D) and Joseph Saenz ${ }^{4}$ \\ ${ }^{1}$ German Center for Neurodegenerative Diseases (DZNE), Greifswald, Germany, ${ }^{2}$ Center for Cognitive \\ Science, University of Kaiserslautern, Kaiserslautern, Germany, ${ }^{3}$ Institute of Social Medicine, Occupational \\ Health and Public Health, University of Leipzig, Leipzig, Germany and ${ }^{4}$ Leonard Davis School of \\ Gerontology, University of Southern California, Los Angeles, CA, USA \\ ${ }^{*}$ Corresponding author. Email: francisca-saveria.rodriguez@dzne.de
}

(Accepted 22 January 2021; first published online 8 March 2021)

\begin{abstract}
Previous studies indicate that occupation might affect cognitive functioning in late life. As people in low- and middle-income countries often have to work until late life, we sought to investigate if there are cognitive benefits to working later into life and whether cognitive function deteriorates after exiting the labour force. We analysed longitudinal data from the Mexican Health and Aging Study (MHAS), a nationally representative sample of Mexican adults age $50+(\mathrm{N}=7,375)$, that assessed cognitive functioning by verbal learning, delayed recall and visual scanning. Analyses were carried out using mixed-effects modelling corrected for the influence of gender, instrumental activities of daily living, diabetes, stroke, hypertension, depression, income and marital status. Results suggest that working actively, compared to exiting the workforce, was associated with cognitive performance only in context with occupation. Domestic workers had a faster decline in verbal learning $(b=$ $-0.02, p=0.020)$ and delayed recall $(b=-0.02, p=0.036)$ if they continued working actively and people working in administration $(b=0.03, p=0.007)$, sales $(b=0.02, p=$ $0.044)$ and educators $(b=0.03, p=0.049)$ had a slower decline in visual scanning if they continued working in old age. Our findings indicate that continued participation in the labour force in old age does not necessarily come with cognitive benefits. Whether or not working actively in later life protects or even harms cognitive functioning is likely to depend on the type of job.
\end{abstract}

Keywords: occupation; retirement decision; cognitive decline; middle-income country; cognition

\section{Introduction}

While population ageing is occurring at a global level (World Health Organization, 2016), this process is occurring especially rapidly in Mexico and Latin America (Wong and Palloni, 2009). The Mexican population aged 60 and over is projected to rise from 3.9 to 16.1 per cent from 2000 to 2050 (Consejo Nacional de Población, 2004). However, population ageing in Mexico has outpaced the development of

(c) The Author(s), 2021. Published by Cambridge University Press. This is an Open Access article, distributed under the terms of the Creative Commons Attribution licence (http://creativecommons.org/licenses/by/4.0/), which permits unrestricted re-use, distribution, and reproduction in any medium, provided the original work is properly cited. 
institutional support systems for aged adults (Wong and Palloni, 2009). Population ageing has also occurred alongside decreases in fertility (Cosío and Ferreiro, 1992), limiting the potential supply of children to care for older adults with physical and cognitive limitations. These population trends have led to increased attention on the predictors of cognitive health and the costs associated with it (Langa et al., 2001; Hurd et al., 2013).

Prior studies of cognitive function among older Mexican adults have highlighted the importance of education and community size (Saenz et al., 2017), health behaviours (Aguilar-Navarro et al., 2007b), lifecourse socio-economic status (Zeki Al Hazzouri et al., 2011) and diabetes (Mejia-Arango and Gutierrez, 2011). However, less research has investigated the associations between occupation throughout the lifecourse and cognitive function in late life in Mexico. This is a considerable omission as research in developed countries has demonstrated important differences in old age cognition by occupation (Dartigues et al., 1992a; Andel et al., 2005; Smart et al., 2014). Previous studies indicate that having poor memory is more than twice as high for farmers, domestic workers and blue-collar workers compared to managers (Dartigues et al., 1992b). In an Australian study, employees in trade, technology and some service occupations were also more likely to have dementia (Jorm et al., 1998). Results from a population-based study in France point out that the risk of farmworkers having cognitive impairments is about six times and of domestic workers about three times as high (Dartigues et al., 1992a). Occupations with the lowest risk for dementia seem to be managers (Helmer et al., 2001). There seems to be a tendency for manual work to come with a higher dementia risk (Qiu et al., 2003) and for sedentary occupations to come with a lower dementia risk (Anttila et al., 2002). Findings are explained with the intellectual complexity of the job. People who have occupations with greater complexity tend to have better cognitive functioning in old age (Finkel et al., 2009) and seem to have a lower dementia risk (Then et al., 2014).

These observations are explained by the 'use it or lose it hypothesis' which posits that engaging in intellectual activities may prevent cognitive abilities from declining (Salthouse, 2006). 'Using' intellectual capacities leads to an activation of neurons, a process that may interfere with the process of ageing by upregulating the neuronal biochemical activity including neurotransmitters and hormones (Swaab, 1991). Intellectual stimulation at work might do exactly this, as results from different studies show (Then et al., 2014, 2017). Occupation may, thus, be an important determinant of cognitive function in late life. However, not all studies confirm that engaging in intellectual activities protects against cognitive decline (Staff et al., 2018). Hence, it might be a question of what type of activities a person engages in that determines whether cognitive capacities will be lost.

It is unclear both whether there are similar cognitive benefits to working later into life and whether cognitive function deteriorates after exiting the labour force. Results from the Swedish Adoption/Twin Study of Aging show that, before retirement, greater occupational complexity was associated with better cognitive performance in verbal abilities, but, after retirement, greater occupational complexity was associated with faster decline in spatial reasoning (Finkel et al., 2009). This conclusion suggests that late retirement may protect cognitive abilities. Indeed, results from the longitudinal French Three-City cohort study indicate that retiring 
later in life is associated with a lower dementia risk (Grotz et al., 2015). It seems that retiring later in life delays the age of onset of dementia (Lupton et al., 2010). However, the answer might not be as simple as this. Findings from the Health and Retirement Study (HRS) highlight that the decision to retire always led to worse cognitive functioning in people with a low level of occupational complexity, but not in those with high complexity (Carr et al., 2020). Further evidence shows that individuals with higher mental demands at work had a better cognitive functioning before retirement and a slower rate of cognitive decline after retirement (Fisher et al., 2014). Hence, working later in life might only come with benefits for a certain occupational group.

Moreover, the effects of working in older age might not be the same in developed and less-developed countries. The Mexican occupational context differs from that of the United States of America (USA) in several important ways. Older adults in Mexico are more likely to have been employed in different types of occupations throughout the lifecourse than older adults in the USA and other developed countries, with labour in the agricultural sector making up a considerably larger share of total employment in Mexico (World Bank, 2017). Mexico also contains a large and stable informal labour sector (Instituto Nacional de Estadística y Geografía, 2017), with the share of informal labourers differing substantially by work activity, and informal labourers concentrated at lower levels of the income distribution (Gasparini and Tornarolli, 2009). Female labour force participation in Mexico, although rising, has also lagged behind the USA and other Organisation for Economic Co-operation and Development countries (Besamusca et al., 2015). The unique context of labour in Mexico implies that older Mexican adults may arrive in old age having interacted with a labour market quite different from the USA and other developing countries. Furthermore, the Mexican retirement pension system is unsustainable, unattainable for many Mexicans and far from including those living in poverty (Calvo et al., 2010). Many Mexicans, especially those with low education and income, have difficulties getting the chance to participate in saving up pension funds and/or have only low pension funds (Tuesta, 2017). Economic resources, however, are a very influential factor driving retirement decisions (Barnes-Farrell, 2003), so that many Mexicans have to continue working in old age.

This study aimed to evaluate variation in cognitive function in old age according to occupation in the context of a developing country. We examined whether, among Mexican adults age 50 and older, baseline cognitive function differs across occupational categories, whether participation versus exiting the labour force in old age affects cognitive functioning, and to what extent the type of occupation moderates associations between labour force participation and cognitive function. Given that there seems to be a protective effect of work on cognition, we hypothesise that working actively in older age comes with a slower cognitive decline (Hypothesis 1). Moreover, based on previous studies, we hypothesise that manual occupations as well as farm and domestic workers have a lower cognitive function and faster cognitive decline (Hypothesis 2). Further, our analyses focus on performance in cognitive tests on verbal learning, delayed recall and visual scanning, abilities that naturally decline with ageing (Salthouse, 2009). While visual scanning is a marker for attention in ageing (Trick and Enns, 1998), verbal learning and delayed recall 
are a high-risk indicator for progression to dementia (Prado et al., 2019). If the 'use it or lose it hypothesis' is domain-specific (i.e. only those cognitive abilities used at work are maintained better), then we hypothesise that different occupational types might have different effects on those cognitive abilities (Hypothesis 3).

\section{Methods}

\section{Data}

We used longitudinal data from the Mexican Health and Aging Study (MHAS) (Wong et al., 2015a). The MHAS began in 2001 as a nationally representative, household-based sample of older Mexican adults (age 50 and over) that is comparable to the US HRS. In stratified random population sampling, a nationally representative sample of individuals born prior to 1951 from both rural and urban areas distributed in all 32 states of the country were selected to participate in the study (for more details, see Wong et al., 2017). Follow-up assessments have been conducted in 2003, 2012 and 2015. The MHAS collected data spanning several domains, including chronic health conditions, mental health, income and employment, among others (explained in greater detail by Wong et al., 2015a) by visiting randomly selected individuals in their homes and interviewing them face-to-face. Data files are available at www.MHASweb.org. The MHAS study protocol was approved by the Institutional Review Board or Ethics Committee of the University of Texas Medical Branch, the INEGI in Mexico and the Instituto Nacional de Salud Pública (INSP) in Mexico.

From $\mathrm{N}=15,402$ respondents in the baseline assessment in 2001, we excluded $\mathrm{N}$ $=1,723$ participants because they were not yet age 50 , and an additional $\mathrm{N}=95$ respondents with missing data on education, $\mathrm{N}=2,652$ with missing data on occupation and $\mathrm{N}=3,171$ with missing data on performance in the cognitive test that we used in this analysis. The model did not predict a propensity score for 386 participants because they had missing or invalid values on either of the variables. Thus, we excluded those from our analyses. Analyses of differences between those included and those excluded from the analysis due to missing data suggest that those excluded were significantly more likely to be women, be younger, have less education, have impaired instrumental activities of daily living (IADLs), have had cancer, diabetes, hypertension, stroke or depressive symptoms, were less likely to be working, and have a slightly lower income (for details, see Table S1 in the online supplementary material). Our sample for analysis comprised $\mathrm{N}=7,375$ respondents at baseline. For the follow-up assessment in 2003, our sample comprised 6,835 participants, for 2012, 4,957 participants and for 2015, 4,634 participants. People lost to follow-up in 2015 were significantly older (mean 64.7 versus 58.5 years, $F=1,021.39, p<0.001)$, more likely to be men $(56.9 \%$ versus $51.3 \%$, $\left.\chi^{2}=20.46, p<0.001\right)$ and to be in the lowest income quintile $(22.3 \%$ versus $16.1 \%, \chi^{2}=44.81, p<0.001$ ), had worked longer (mean 35.5 versus 31.3 years, $F$ $=92.97, p<0.001)$ and were less likely to be working at the start of study $(48.5 \%$ versus $60.5 \%, \chi^{2}=93.78, p<0.001$ ), had slightly more symptoms of depression (mean 3.5 versus $3.3, F=10.56, p=0.001$ ), were more likely to have impaired IADLs (7.5\% versus $\left.3.7 \%, \chi^{2}=48.42, p<0.001\right)$, diabetes $\left(22.1 \%\right.$ versus $10.9 \%, \chi^{2}$ $=162.23, p<0.001)$, hypertension $\left(40.5 \%\right.$ versus $\left.34.2 \%, \chi^{2}=27.54, p<0.001\right)$ or 
stroke $\left(2.9 \%\right.$ versus $\left.1.5 \%, \chi^{2}=18.19, p<0.001\right)$. There was no significant difference with respect to the type of job $\left(\chi^{2}=22.64, p=0.124\right)$, whether they worked in similar jobs all their life $\left(\chi^{2}=2.92, p=0.087\right)$ and the number of years of education $(F=2.33, p=0.127)$.

\section{Cognitive function}

Cognitive function in the MHAS is assessed using the Cross Cultural Cognitive Examination (CCCE; Glosser et al., 1993). The CCCE is preferred for populations with low levels of education or limited literacy and mathematical abilities (Zeki Al Hazzouri et al., 2011). While the CCCE evaluates cognition across several domains, we limited our analyses to verbal learning, delayed verbal recall and visual scanning, and omitted other domains (visuospatial abilities, visual memory) with limited score ranges (range $0-2$, possible scores $0 / 1 / 2$, mean change over follow-up period 0.65 and 0.08 ). Verbal learning was assessed by having respondents recall an eightword list three times and calculated by taking the average number of words recalled across attempts (range 0-8). Delayed recall was assessed by having respondents recall the eight-word list after a delay (range 0-8). Both tests measure episodic memory, one the learning aspect and one the recall aspect (Beck et al., 2012), and are good predictors for progression to dementia (Belleville et al., 2017). Visual scanning involves having respondents identify a stimulus in a visual array of different stimuli in one minute (range 0-60). The test on visual scanning measures selective attention (Eizenman et al., 2003). In regression analyses, the $z$-scores of the test scores were used for easier interpretation. As in this study, the CCCE is often analysed using the individual cognitive test scores and thus treats cognition as a continuous variable (e.g. Glosser et al., 1994; Saenz et al., 2018). In general, the CCCE has demonstrated high sensitivity and specificity for dementia (Wolfe et al., 1992; Mejia-Arango and Gutierrez, 2011).

\section{Occupation and working status}

During the interview, the participants were asked about their occupation. The answer that they provided to the question 'What is the name of the office, profession or place where you worked in your main job?' was categorised by the study team according to the Mexican classification of occupations of the Instituto Nacional de Estadística y Geografía (National Institute of Statistics and Geography of Mexico, INEGI) into occupational types. The INEGI occupational classification was developed by and is used by the Mexican National Institute of Statistics. The study team of the MHAS provided the data already coded accordingly. For our analysis, we only combined occupational groups of few people to larger occupational groups (i.e. labourers = labourers, operators, professionals, security, artistic; supervisors = supervisors, directors, department heads). In addition, participants were asked 'In this main job, most of your time were you selfemployed?' and 'Regarding the activities that you normally do at work, would you consider them to be similar to or the same as the activities that you have performed most of your life?' In the analyses, we will first report on the main job that the participants reported at baseline to have done throughout their life. The mixed- 
model analyses, however, will treat their main job as a time-varying variable and thus incorporate changes to the main job. Working status was assessed with the question 'Last week did you work?' Additionally, participants were asked 'About how many hours do you work in a usual day?', but large amounts of missing data prevented further analysis of this question.

\section{Covariates}

Covariates used in this analysis included age, sex, marital status, educational attainment, income and chronic health conditions. Educational attainment was based on years of formal education. In the analyses, the years of education that an individual completed were used as a continuous variable. Income was divided in quintiles for the purpose of analysis. Chronic health conditions were based on self-reported doctor-diagnosed cancer, respiratory illnesses, diabetes, hypertension and stroke. Depressive symptoms were ascertained using a nine-item version of the Center for Epidemiologic Studies - Depression (CES-D) scale (Radloff, 2016) which has been validated for older Mexican adults in previous work (Aguilar-Navarro et al., 2007a). Limitations in IADLs were assessed by reporting difficulty in preparing meals, shopping, taking medications and managing money. Impaired IADLs were defined as at least one impairment in any IADL.

\section{Statistical analysis}

All statistical analyses employed an alpha level for statistical significance of 0.05 (two-tailed) and were performed using Stata 14.2. Descriptive analyses were conducted applying the population weights provided by the MHAS study research team.

As most of our covariates (gender, IADLs, diabetes, stroke, hypertension, CES-D, income and marital status) were significantly associated with the predictors as well as the dependent variable, we used a propensity score to combine the covariates (a commonly applied method; Cavuto et al., 2006; Fang et al., 2010; Biondi-Zoccai et al., 2011). In this way, we avoid problems with multicollinearity in the final models. The propensity score was calculated via inverse-probabilityweighted regression estimating potential-outcome means. The model for the propensity score included an outcome model to predict performance in each of the cognitive tests and a treatment model predicting the active participation in the labour force: a linear outcome model for the propensity score regressed gender, IADLs, diabetes, stroke, hypertension, CES-D, income and marital status on performance in all three cognitive tests; a multinominal logit treatment model regressed gender, IADLs, diabetes, stroke, hypertension, CES-D, income and marital status on working status (yes/no: indicator variable for being an active part of the workforce in each study year). The inverse-probability-weighted estimated means of the combined models reflect the propensity score.

Characteristics of the study sample were estimated via sampling weight-adjusted proportions and means using logit transformation. Significant differences by occupational group and by working status were tested using the Adjusted Wald Test for categorical variables and survey-based variance estimates for correlations for 
continuous variables. Associations between occupation, working status and cognitive performance at baseline were first estimated via the Adjusted Wald Test and then linear regression analysis adjusted for working status, education, age and propensity score. For regression analysis, production workers were used as the reference group because they were the largest occupational group who also had low levels of mental demands at work and low educational attainment, and because they made up the same amount among those who stopped working (17\%) and those who continued working over the study period (17\%).

Associations between occupation categories, working status and cognitive performance over the follow-up period (2001-2015) were estimated via mixed models using age as the time variable and with random effects for education and the propensity score. We also included a squared effect of the time variable in the model, as cognition is considered to decline in a non-linear way, and autoregressive residuals because cognitive performance is dependent on the cognitive performance from the previous timepoint. Model 1 focused on working status and did not include occupation; Model 2 included occupation. The advantage of using mixed models is that the models allow occupation and working status to vary across the follow-up points (i.e. the model included estimations if a participant changed his or her job). The variables for occupation and working status therefore specify for each assessment wave whether the participant was still participating in or had exited the workforce. As a form of sensitivity analysis, we repeated Model 2 including an additional three-way interaction effect for occupation with working status and with time.

\section{Results}

Of our sample, 53.6 per cent were men, 69.9 per cent were married, 4.4 per cent had impaired IADLs and the mean age at baseline was 60.5 years (standard deviation $(\mathrm{SD})=8.4$, range $=50-105$ years). The average years of education completed were $5.10(\mathrm{SD}=4.58)$. Details of the socio-economic characteristics are shown in Table 1. Participation in the workforce at the start of the study in 2001 was 56.3 per cent (population-representative percentage, study $\mathrm{N}=4,159$ ). A total of 29.7 per cent of older Mexicans (population-representative percentage, study $\mathrm{N}=$ $1,943)$ were self-employed and 65.7 per cent had worked in similar occupations all their life. The distribution of employment types, socio-economic characteristics and work history by occupational groups are displayed in Table S2 in the online supplementary material.

\section{Exiting the workforce}

In 2003, a total of $\mathrm{N}=906$ of those who were working in $2001(\mathrm{~N}=4,159)$ stopped working (population-representative 23.2\%). By 2012, another $\mathrm{N}=1,610$ stopped working (population-representative 52.9\%) and by 2015, an additional $\mathrm{N}=484$ participants (population-representative 33.9\%) stopped working (details in Table S3 in the online supplementary material). However, 453 participants who had stopped working and 683 participants who were not working at baseline started working again at a later point of the study. There was no significant difference 
Table 1. Socio-economic and demographic characteristics at study baseline (2001)

\begin{tabular}{|c|c|c|c|}
\hline & $\mathrm{N}$ & $\%$ (sampling weight-adjusted) & $\mathrm{Cl}$ \\
\hline \multicolumn{4}{|l|}{ Gender: } \\
\hline Male & 3,915 & 53.6 & $51.4,55.8$ \\
\hline Female & 3,460 & 46.4 & $44.2,48.6$ \\
\hline \multicolumn{4}{|l|}{ IADLs: } \\
\hline Not impaired & 7,010 & 95.6 & $94.8,96.4$ \\
\hline Impaired & 365 & 4.4 & $3.6,5.2$ \\
\hline \multicolumn{4}{|l|}{ Cancer: } \\
\hline No & 7,240 & 98.4 & $97.8,98.8$ \\
\hline Yes & 132 & 1.6 & $1.2,2.2$ \\
\hline \multicolumn{4}{|c|}{ Respiratory conditions: } \\
\hline No & 6,911 & 94.3 & $93.2,95.2$ \\
\hline Yes & 462 & 5.7 & $4.8,6.8$ \\
\hline \multicolumn{4}{|l|}{ Diabetes: } \\
\hline No & 6,303 & 85.8 & $84.1,87.3$ \\
\hline Yes & 1,072 & 14.2 & $12.7,15.9$ \\
\hline \multicolumn{4}{|l|}{ Hypertension: } \\
\hline No & 4,702 & 64.7 & $62.5,66.7$ \\
\hline Yes & 2,673 & 35.3 & $33.3,37.5$ \\
\hline \multicolumn{4}{|l|}{ Stroke: } \\
\hline No & 7,232 & 98.3 & $97.8,98.7$ \\
\hline Yes & 143 & 1.7 & $1.3,2.2$ \\
\hline \multicolumn{4}{|l|}{ Income quintile: } \\
\hline Very low & 1,336 & 20.9 & $19.1,22.9$ \\
\hline Low & 1,440 & 19.8 & $18.2,21.5$ \\
\hline Medium & 1,507 & 19.2 & $17.7,20.9$ \\
\hline High & 1,527 & 19.9 & $18.2,21.8$ \\
\hline Very high & 1,565 & 20.1 & $18.3,22.0$ \\
\hline \multicolumn{4}{|l|}{ Marital status: } \\
\hline Married & 5,230 & 69.9 & $67.7,72.0$ \\
\hline Widowed & 1,134 & 15.5 & $13.9,17.2$ \\
\hline Other & 1,011 & 14.6 & $12.9,16.5$ \\
\hline \multicolumn{4}{|l|}{ Active working: } \\
\hline No & 3,190 & 43.7 & $41.6,45.6$ \\
\hline Yes & 4,159 & 56.3 & $54.0,58.4$ \\
\hline
\end{tabular}


Table 1. (Continued.)

\begin{tabular}{|c|c|c|c|}
\hline & $\mathrm{N}$ & $\%$ (sampling weight-adjusted) & $\mathrm{Cl}$ \\
\hline \multicolumn{4}{|c|}{ Working, no pay: } \\
\hline No & 4,723 & 61.0 & $58.9,63.2$ \\
\hline Yes & 2,578 & 39.0 & $36.8,41.1$ \\
\hline \multicolumn{4}{|c|}{ Self-employed: } \\
\hline No & 5,379 & 70.3 & $68.3,72.3$ \\
\hline Yes & 1,943 & 29.7 & $27.7,31.7$ \\
\hline \multicolumn{4}{|c|}{ Similar work all life: ${ }^{1}$} \\
\hline No & 1,201 & 34.3 & $31.0,37.8$ \\
\hline Yes & 1,893 & 65.7 & $62.2,68.9$ \\
\hline
\end{tabular}

Notes: $\mathrm{N}=7,375 . \mathrm{Cl}$ : $95 \%$ confidence interval with sampling weights adjusted. IADLs: instrumental activities of daily living. 1. Among those working in 2001.

between occupational groups (details in Table S3 in the online supplementary material).

\section{Cognitive performance at baseline \\ Verbal learning}

An Adjusted Wald Test indicated that performance in verbal learning was significantly better among those who were female, did not have impaired IADLs, had not had a stroke, were married, had a higher income, were working a paid job and were not self-employed, but not for working actively compared to not working anymore (see Table 2). Significant correlations were observed between better verbal learning performance and lower CES-D score $(-0.106, p<0.001)$, younger age $(-0.289, p<$ $0.001)$ and a higher education $(0.349, p<0.001)$. Results from a linear regression on verbal learning ( $z$-score, adjusted for education and propensity score) indicated that those working actively had a significantly poorer performance $(b=-0.099, p=$ $0.018)$ and, compared to production workers, those who worked in administration $(b=0.237, p=0.014)$, sales $(0.288, p<0.001)$, as technicians $(b=0.268, p=0.011)$ and as domestic workers $(b=0.140, p=0.049)$ had significantly better performance (pairwise comparisons in Table S4 in the online supplementary material).

\section{Delayed recall}

An Adjusted Wald Test indicated that performance in delayed recall was significantly better among females, those who did not have impaired IADLs, had not had a stroke, did not have diabetes, were married, with a higher income, and were not selfemployed, but not for working actively compared to not working anymore (see Table 2). A better performance correlated significantly with a lower CES-D score $(-0.048, p<0.001)$, younger age $(-0.241, p<0.001)$ and higher education $(0.189$, $p<0.001)$. Results from a linear regression on delayed recall $(z$-score, adjusted for confounders) indicated that working actively was non-significant $(b=-0.050, p=$ 
Table 2. Differences in cognition by participants' characteristics at study baseline (2001)

\begin{tabular}{|c|c|c|c|}
\hline & Verbal learning & Delayed recall & Visual scanning \\
\hline & \multicolumn{3}{|l|}{ Mean values $(\mathrm{Cl})$} \\
\hline \multicolumn{4}{|l|}{ Gender: } \\
\hline Male & $4.5(4.5,4.6)^{\star \star \star}$ & $4.9(4.8,5.0)^{\star \star \star}$ & $24.4(23.6,25.2)$ \\
\hline Female & $4.8(4.7,4.9)$ & $5.2(5.1,5.3)$ & $23.2(22.3,24.2)$ \\
\hline \multicolumn{4}{|l|}{ IADLs: } \\
\hline Not impaired & $4.7(4.6,4.7)^{\star \star}$ & $5.1(5.0,5.1)^{\star \star}$ & $24.1(23.4,24.7)^{\star \star \star}$ \\
\hline Impaired & $4.4(4.2,4.6)$ & $4.7(4.4,5.0)$ & $19.4(17.0,21.7)$ \\
\hline \multicolumn{4}{|l|}{ Cancer: } \\
\hline No & $4.6(4.6,4.7)$ & $5.0(5.0,5.1)$ & $23.8(23.2,24.5)$ \\
\hline Yes & $4.7(4.3,5.1)$ & $5.1(4.6,5.7)$ & $25.1(21.3,28.9)$ \\
\hline \multicolumn{4}{|c|}{ Respiratory conditions: } \\
\hline No & $4.7(4.6,4.7)$ & $5.0(5.0,5.1)$ & $23.9(23.2,24.5)$ \\
\hline Yes & $4.6(4.4,4.8)$ & $5.1(4.8,5.3)$ & $23.4(21.0,25.8)$ \\
\hline \multicolumn{4}{|l|}{ Diabetes: } \\
\hline No & $4.7(4.6,4.7)$ & $5.1(5.0,5.2)^{\star \star \star}$ & $24.0(23.3,24.7)$ \\
\hline Yes & $4.6(4.4,4.7)$ & $4.7(4.5,4.9)$ & $22.9(21.2,24.7)$ \\
\hline \multicolumn{4}{|l|}{ Hypertension: } \\
\hline No & $4.6(4.6,4.7)$ & $5.0(4.9,5.1)$ & $24.0(23.3,24.8)$ \\
\hline Yes & $4.7(4.6,4.8)$ & $5.1(4.9,5.2)$ & $23.5(22.5,24.5)$ \\
\hline \multicolumn{4}{|l|}{ Stroke: } \\
\hline No & $4.7(4.6,4.7)^{\star \star \star}$ & $5.1(5.0,5.1)^{\star}$ & $24.0(23.3,24.6)^{\star \star \star}$ \\
\hline Yes & $4.0(3.6,4.3)$ & $4.2(3.5,4.9)$ & $17.3(14.8,19.8)$ \\
\hline \multicolumn{4}{|l|}{ Income quintile: } \\
\hline Very low & $4.5(4.3,4.6)^{\star \star \star}$ & $4.9(4.8,5.1)^{\star \star}$ & $19.7(18.6,20.9)^{\star \star \star}$ \\
\hline Low & $4.4(4.3,4.6)$ & $4.8(4.6,4.9)$ & $21.3(20.1,22.5)$ \\
\hline Medium & $4.6(4.5,4.7)$ & $5.0(4.9,5.1)$ & $24.1(22.9,25.4)$ \\
\hline High & $4.8(4.7,4.9)$ & $5.2(5.0,5.4)$ & $25.2(23.8,26.6)$ \\
\hline Very high & $5.0(4.8,5.1)$ & $5.3(5.1,5.5)$ & $29.1(27.3,30.9)$ \\
\hline \multicolumn{4}{|l|}{ Marital status: } \\
\hline Married & $4.7(4.6,4.7)^{\star \star}$ & $5.1(5.0,5.2)^{\star \star \star}$ & $24.7(24.0,25.4)$ \\
\hline Widowed & $4.3(4.2,4.5)$ & $4.8(4.6,5.0)$ & $18.9(17.5,20.3)$ \\
\hline Other & $4.8(4.7,4.9)$ & $5.0(4.8,5.2)$ & $25.1(23.4,26.8)$ \\
\hline \multicolumn{4}{|l|}{ Actively working: } \\
\hline No & $4.6(4.6,4.7)$ & $5.0(4.9,5.1)$ & $22.2(21.3,23.1)^{\star \star \star}$ \\
\hline Yes & $4.7(4.6,4.7)$ & $5.1(5.0,5.2)$ & $25.1(24.3,26.0)$ \\
\hline
\end{tabular}


Table 2. (Continued.)

\begin{tabular}{|c|c|c|c|}
\hline & Verbal learning & Delayed recall & Visual scanning \\
\hline \multicolumn{4}{|l|}{ Self-employed job: } \\
\hline No & $4.7(4.7,4.8)^{\star \star \star}$ & $5.1(5.0,5.2)^{\star \star \star}$ & $25.1(24.4,25.9)^{\star \star \star}$ \\
\hline Yes & $4.4(4.3,4.5)$ & $4.8(4.7,5.0)$ & $20.9(19.8,22.0)$ \\
\hline \multicolumn{4}{|l|}{ Changed job: ${ }^{1}$} \\
\hline No & $4.7(4.6,4.7)$ & $5.0(4.9,5.1)$ & $23.2(22.3,24.1)^{\star}$ \\
\hline Yes & $4.6(4.6,4.7)$ & $5.1(5.0,5.2)$ & $24.6(23.7,25.4)$ \\
\hline \multicolumn{4}{|l|}{ Occupation: ${ }^{2}$} \\
\hline Production worker & $4.5(4.4,4.6)$ & $4.7(4.6,4.9)$ & $24.8(23.3,26.2)$ \\
\hline Administration & $5.2(5.0,5.4)$ & $5.4(5.1,5.6)$ & $33.2(30.1,36.4)$ \\
\hline Artistic & $4.7(3.9,5.5)$ & $4.4(3.2,5.6)$ & $32.8(25.5,40.0)$ \\
\hline Department head & $5.0(4.6,5.3)$ & $5.4(4.8,6.0)$ & $35.2(30.8,39.5)$ \\
\hline Director & $5.4(5.0,5.9)$ & $5.9(5.4,6.3)$ & $37.6(33.0,42.2)$ \\
\hline Domestic worker & $4.6(4.4,4.7)$ & $5.1(4.9,5.3)$ & $17.3(16.1,18.4)$ \\
\hline Driver & $4.5(4.3,4.8)$ & $4.8(4.5,5.1)$ & $27.2(24.8,29.6)$ \\
\hline Educator & $5.4(5.2,5.6)$ & $5.7(5.4,6.0)$ & $36.0(32.3,39.8)$ \\
\hline Labourer & $4.5(4.2,4.7)$ & $4.7(4.2,5.1)$ & $20.7(18.4,23.0)$ \\
\hline Operator & $4.7(4.4,5.0)$ & $5.0(4.6,5.4)$ & $27.0(24.4,29.7)$ \\
\hline Professional & $5.6(5.3,5.8)$ & $5.9(5.6,6.2)$ & $36.0(27.2,44.8)$ \\
\hline Sales & $5.0(4.9,5.1)$ & $5.2(5.0,5.4)$ & $26.1(24.3,27.8)$ \\
\hline Security & $4.5(4.2,4.9)$ & $4.9(4.4,5.5)$ & $26.1(24.3,27.8)$ \\
\hline Service & $4.6(4.4,4.9)$ & $4.9(4.5,5.2)$ & $22.9(20.0,25.9)$ \\
\hline Supervisor & $5.1(4.7,5.5)$ & $5.4(4.7,6.1)$ & $33.1(28.8,37.4)$ \\
\hline Technician & $5.3(5.0,5.5)$ & $5.7(5.3,6.1)$ & $33.8(29.3,38.4)$ \\
\hline Worker (A/L) & $4.2(4.1,4.3)$ & $4.8(4.7,5.0)$ & $17.5(16.5,18.4)$ \\
\hline
\end{tabular}

Notes: $N=7,375$. Range of scores in cognitive testing: verbal learning $0-8$; delayed recall $0-8$; visual scanning $0-60$ (higher scores indicating a better performance). $\mathrm{Cl}$ : $95 \%$ confidence interval with sampling weights adjusted. IADLs: instrumental activities of daily living. A/L: agriculture or livestock. 1. Before or during study. 2. A pairwise comparison was not run, see the results of the regression analyses in Table S4 in the online supplementary material. 3. Among those working in 2001. Significance levels: ${ }^{*} p<0.05,{ }^{\star \star} p<0.01,{ }^{\star \star \star} p<0.001$ (Adjusted Wald Test).

$0.247)$ and, compared to production workers, those who worked in sales $(b=0.188, p$ $=0.010)$, as supervisors/directors $(b=0.283, p=0.006)$, domestic workers $(b=0.266$, $p=0.001)$ and technicians $(b=0.339, p=0.017)$ had significantly better performance (pairwise comparisons in Table S4 in the online supplementary material).

\section{Visual scanning}

An Adjusted Wald Test indicated that performance in visual scanning was significantly better among those who were actively working, did not have impaired 
IADLs, had not had a stroke, had a higher income and were not self-employed (see Table 2). Significant correlations were observed between better visual scanning performance and a lower CES-D score $(-0.180, p<0.001)$, younger age $(-0.327, p<$ $0.001)$ and higher education $(0.521, p<0.001)$. Results from a linear regression of occupation on visual scanning ( $z$-score, adjusted for confounders) indicated that working actively was non-significant $(b=0.045, p=0.239)$ and, compared to production workers, those who worked as domestic workers $(b=-0.336, p<0.001)$, labourers (including operators, professionals, security and arts: $b=-0.165, p=$ $0.032)$, and workers in agriculture and with livestock $(b=-0.324, \mathrm{p}<0.001)$ had significantly worse visual scanning performance (pairwise comparisons in Table S4 in the online supplementary material).

\section{Cognitive performance during follow-up period}

Associations between occupation and actively working on cognitive performance over the study period (2001-2015) were estimated by mixed models with random effects for education and the propensity score (results and effect estimates are shown in Table 3). Treating working status as a time-varying variable, the results indicate that working actively (compared to exiting the workforce) was not associated with cognitive performance in Model 1 (trends for verbal learning $\chi^{2}=$ $0.43, p=0.514$; delayed recall $\chi^{2}=3.07, p=0.079$; visual scanning $\chi^{2}=2.56, p=$ 0.109 ). Only if occupation was added (Model 2) was working actively associated with a poorer performance in verbal learning and delayed recall, as well as a slower decline in all cognitive tests with ageing (see Table 3, trends for verbal learning $\chi^{2}=$ $13.55, p<0.001$; delayed recall $\chi^{2}=16.00, p<0.001$; visual scanning $\chi^{2}=1.78, p=$ 0.182 ). Figure $1 \mathrm{~A}$ shows decline in performance in verbal learning and delayed recall of educators compared to production workers. Figure $1 \mathrm{~B}$ shows decline of performance in visual scanning of technicians and of those who worked in agriculture and with livestock compared to production workers. Accordingly, Hypothesis 1 that working actively in older age comes with a slower cognitive decline cannot be confirmed in general, but seems to be occupation-specific.

To test for interaction effects of working status with occupation, we repeated the previous models of cognitive performance over the follow-up period including a three-way interaction for occupation with working status and with time (results in Table S5 in the online supplementary material). Results suggest that, compared to production workers, domestic workers had a significantly faster decline in verbal learning $(b=-0.02, p=0.020)$ and in delayed recall $(b=-0.02, p=0.036)$ if they continued working actively in contrast to exiting the workforce (see Figure 2A). Results also suggested that, compared to production workers, those working in administration $(b=0.03, p=0.007)$, sales $(b=0.02, p=0.044)$ and educators $(b=$ $0.03, p=0.049)$ had a slower decline in visual scanning if they continued working (see Figure $2 \mathrm{~B}$ ). Adding a random slope for occupation to the model confirmed these findings (results not shown). Accordingly, the results confirm Hypothesis 2 that manual or non-intellectual occupations have a faster cognitive decline only with respect to visual scanning but not with respect to verbal learning and delayed recall. The results also suggest that Hypothesis 3 is correct, indicating a domainspecific effect of occupational types. 


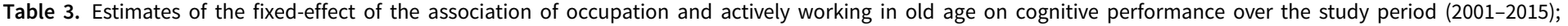
estimated by mixed models with random effects (not shown) for age, education and the propensity score with autoregressive residuals

\begin{tabular}{|c|c|c|c|c|}
\hline & & Verbal learning & Delayed recall & Visual scanning \\
\hline & & \multicolumn{3}{|l|}{$b$ values $(\mathrm{Cl})$} \\
\hline \multicolumn{5}{|l|}{ Model 1: } \\
\hline \multirow[t]{2}{*}{ Actively working } & No & Ref. & Ref. & Ref. \\
\hline & Yes & $-0.06(-0.25,0.13)$ & $-0.18(-0.38,0.02)$ & $0.14(-0.03,0.31)$ \\
\hline \multirow[t]{2}{*}{ Actively working $\times$ age } & No & Ref. & Ref. & Ref. \\
\hline & Yes & $0.00(-0.00,0.00)$ & $0.00(-0.00,0.01)$ & $-0.00(-0.00,-0.00)$ \\
\hline Age & (Continuous) & $0.09(0.08,0.11)^{\star \star \star}$ & $0.09(0.08,0.11)^{\star \star \star}$ & $0.09(0.07,0.10)^{\star \star \star}$ \\
\hline Age (slope) & (Continuous) & $-0.00(-0.00,-0.00)^{\star \star \star}$ & $-0.00(-0.00,-0.00)^{\star \star \star}$ & $-0.00(-0.00,0.00)^{\star \star \star}$ \\
\hline $\mathrm{AIC}$ & & 61,837 & 63,725 & 55,508 \\
\hline \multicolumn{5}{|l|}{ Model 2: } \\
\hline \multirow[t]{2}{*}{ Actively working } & No & Ref. & Ref. & Ref. \\
\hline & Yes & $-0.55(-0.84,-0.25)^{\star \star \star}$ & $-0.61(-0.92,-0.31)^{\star \star \star}$ & $-0.18(-0.45,0.09)$ \\
\hline \multirow[t]{2}{*}{ Actively working $\times$ age } & No & Ref. & Ref. & Ref. \\
\hline & Yes & $0.01(0.00,0.01)^{\star \star \star}$ & $0.01(0.00,0.02)^{\star \star \star}$ & $0.00(0.00,0.01)^{\star}$ \\
\hline \multirow[t]{7}{*}{ Occupation $^{1}$} & Production worker & Ref. & Ref. & Ref. \\
\hline & Administration & $0.69(-0.06,1.44)$ & $-0.08(-0.85,0.69)$ & $0.54(-0.17,1.26)$ \\
\hline & Labourers $^{2}$ & $0.28(-0.23,0.79)$ & $0.15(-0.38,0.69)$ & $0.40(-0.07,0.88)$ \\
\hline & Supervisors $^{3}$ & $0.64(-0.06,1.33)$ & $0.43(-0.29,1.15)$ & $0.54(-0.13,1.22)$ \\
\hline & Domestic worker & $-0.41(-0.92,0.11)$ & $-0.28(-0.81,0.26)$ & $-0.44(-0.90,0.03)$ \\
\hline & Driver & $-0.17(-0.86,0.53)$ & $-0.09(-0.81,0.63)$ & $0.03(-0.59,0.66)$ \\
\hline & Educator & $-0.19(-0.95,0.57)$ & $-0.49(-1.27,0.30)$ & $0.51(-0.26,1.28)$ \\
\hline
\end{tabular}


Table 3. (Continued.)

\begin{tabular}{|c|c|c|c|c|}
\hline & & Verbal learning & Delayed recall & Visual scanning \\
\hline & Sales & $0.28(-0.20,0.77)$ & $0.31(-0.19,0.82)$ & $0.16(-0.28,0.61)$ \\
\hline & Service & $-0.34(-0.96,0.28)$ & $-0.33(-0.98,0.31)$ & $-0.22(-0.78,0.34)$ \\
\hline & Technician & $0.54(-0.32,1.40)$ & $0.71(-0.18,1.59)$ & $0.96(0.14,1.78)^{\star}$ \\
\hline & Worker (A/L) & $-0.11(-0.56,0.34)$ & $0.22(-0.25,0.68)$ & $-0.66(-1.07,-0.26)^{\star \star}$ \\
\hline \multirow[t]{11}{*}{ Occupation $\times$ age } & Production worker & Ref. & & \\
\hline & Administration & $-0.00(-0.02,0.01)$ & $0.01(-0.01,0.02)$ & $-0.00(-0.01,0.01)$ \\
\hline & Labourers $^{2}$ & $-0.00(-0.01,0.01)$ & $-0.00(-0.01,0.01)$ & $-0.01(-0.01,0.00)$ \\
\hline & Supervisors ${ }^{3}$ & $-0.00(-0.01,0.01)$ & $-0.00(-0.01,0.01)$ & $-0.00(-0.01,0.01)$ \\
\hline & Domestic worker & $0.00(-0.00,0.01)$ & $0.00(-0.00,0.01)$ & $-0.00(-0.01,0.01)$ \\
\hline & Driver & $0.00(-0.01,0.01)$ & $0.00(-0.01,0.01)$ & $0.00(-0.01,0.01)$ \\
\hline & Educator & $0.01(0.00,0.03)^{\star}$ & $0.01(0.00,0.03)^{\star}$ & $0.00(-0.01,0.02)$ \\
\hline & Sales & $-0.00(-0.01,0.01)$ & $-0.00(-0.01,0.00)$ & $-0.00(-0.01,0.01)$ \\
\hline & Service & $0.01(-0.00,0.02)$ & $0.01(-0.00,0.02)$ & $0.00(-0.01,0.01)$ \\
\hline & Technician & $-0.00(-0.02,0.01)$ & $-0.01(-0.02,0.01)$ & $-0.01(-0.02,0.01)$ \\
\hline & Worker (A/L) & $-0.00(-0.01,0.00)$ & $-0.01(-0.01,0.00)$ & $0.00(-0.00,0.01)$ \\
\hline Age & (Continuous) & $0.06(0.03,0.08)^{\star \star \star}$ & $0.05(0.02,0.08)^{\star \star \star}$ & $0.04(0.01,0.06)^{\star \star \star}$ \\
\hline Age (slope) & (Continuous) & $-0.00(-0.00,-0.00)^{\star \star \star}$ & $-0.00(-0.00,-0.00)^{\star \star \star}$ & $-0.00(-0.00,-0.00)^{\star \star \star}$ \\
\hline AIC & & 25,557 & 26,164 & 23,836 \\
\hline
\end{tabular}

Notes: $\mathrm{N}=7,375 . b$ : regression coefficient. Cl: $95 \%$ confidence interval with sampling weights adjusted. AIC: Akaike information criterion. Ref.: reference category. A/L: agriculture or livestock. 1. Effects are conditional on 'interaction effects'. 2 . Including operators, professsionals, workers in arts and security. 3. Including directors and department heads. Random effects verbal learning: Model 1 education $b=0.00, \mathrm{Cl}=0.00,0.00, \mathrm{SE}=0.00$; propensity score $b=0.42, \mathrm{Cl}=0.00,7,278.27, \mathrm{SE}=2.07$. Model 2 education $b=0.00, \mathrm{Cl}=0.00,0.00, \mathrm{SE}=0.00 ;$ propensity score $b=2.15$, $\mathrm{Cl}=0.15,30.26, \mathrm{SE}=2.89$. Random effects delayed recall: Model 1 education $b=0.00, \mathrm{Cl}=0.00,0.00, \mathrm{SE}=0.00 ;$ propensity score $b=4.03, \mathrm{Cl}=1.34,12.13, \mathrm{SE}=2.26$. Model 2 education $b=0.00, \mathrm{Cl}=$

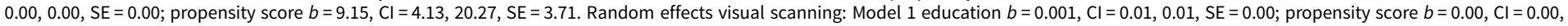
$0.00, \mathrm{SE}=0.00$. Model 2 education $b=0.00, \mathrm{Cl}=0.00,0.00, \mathrm{SE}=0.00$; propensity score $b=0.00, \mathrm{Cl}=0.00,0.00, \mathrm{SE}=0.00$.

Significance levels: ${ }^{\star} p<0.05,{ }^{\star \star} p<0.01,{ }^{\star \star \star} p<0.001$. 
(a) ${ }^{1}$
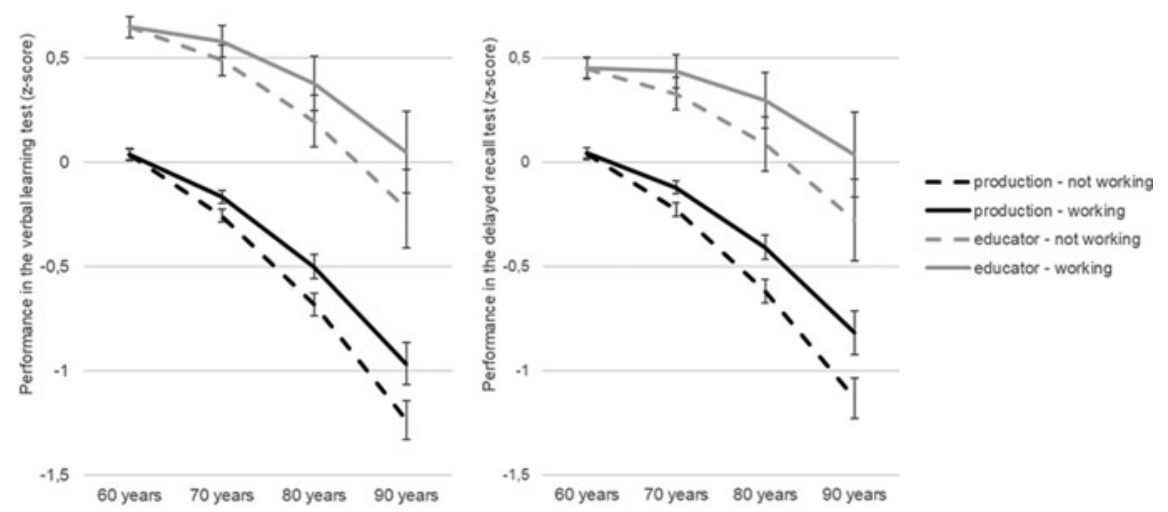

(b) 1

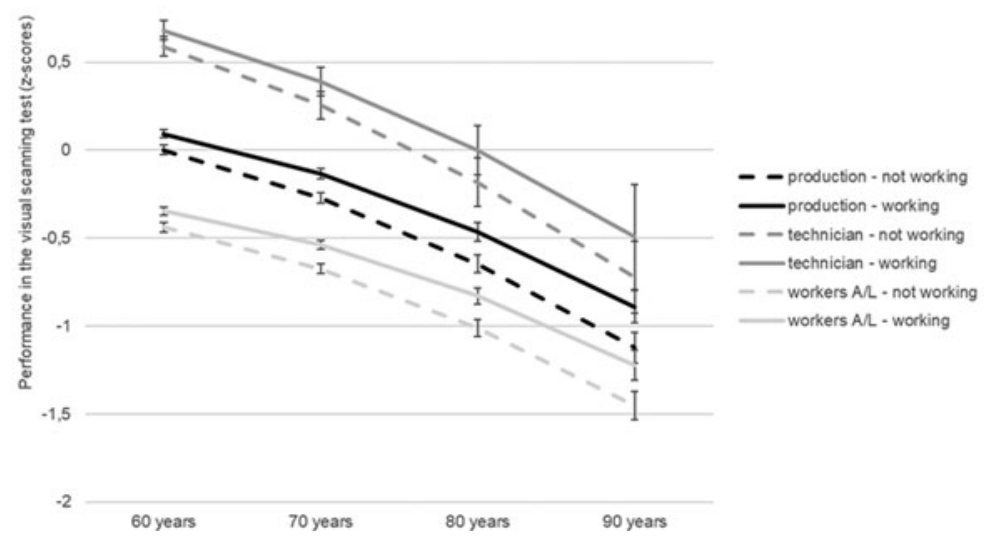

Figure 1. Predicted score in the cognitive tests by working status and occupation, as predicted by the mixed models using year as time and with random effects for education and the propensity score. Note: A/L: agriculture or livestock.

\section{Discussion}

The aim of this study was to examine whether participation versus exiting the labour force in old age affects cognitive functioning among older Mexican adults, and to what extent the type of occupation moderates this association. Our results from longitudinal observations of a population-based study suggest that participating in the workforce in general is not associated with cognitive functioning in ageing (Hypothesis 1); but for some occupations working longer might slow down the decline in memory (verbal learning and delayed recall). Further, the results do not confirm the general notion that manual or non-intellectual occupations have a faster cognitive decline (Hypothesis 2) as we observe this trend only with respect to visual scanning but not with respect to verbal learning and delayed recall. Accordingly, our findings emphasise the relevance of domain-specific effects of occupational types (Hypothesis 3), indicating that the 'use it or lose it hypothesis' is domain-specific 
(a)
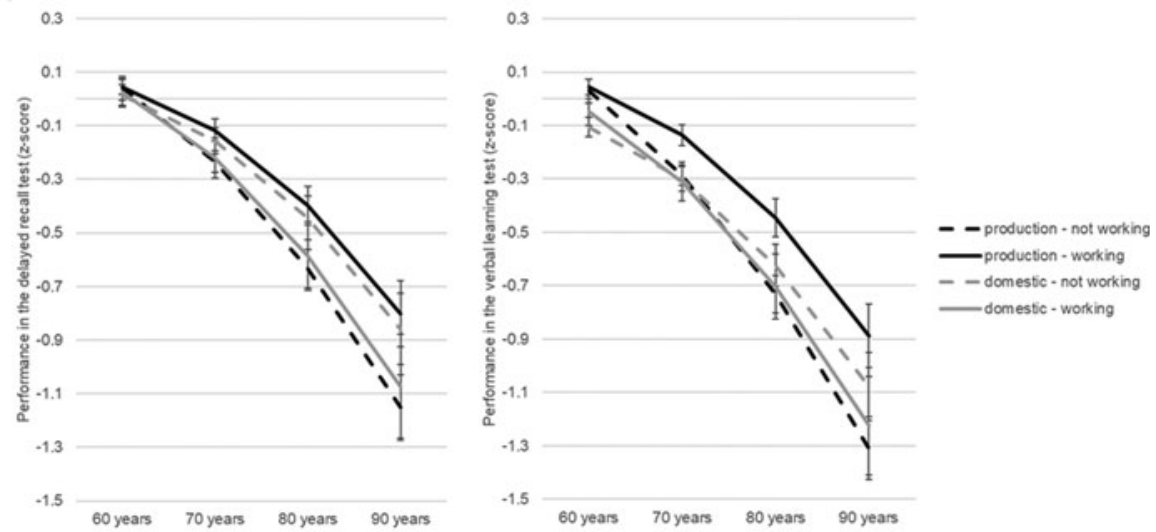

(b)

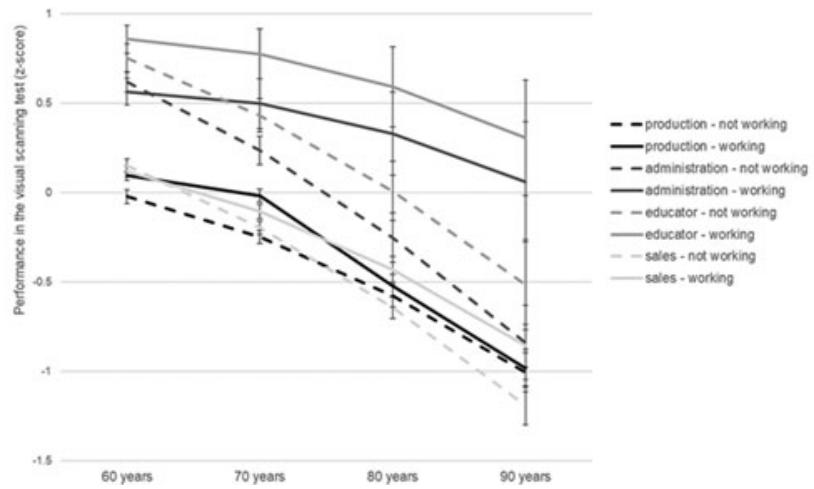

Figure 2. Predicted score in the visual scanning task by working status and occupation in interaction with ageing, as predicted by the mixed models using age as the time variable and with random effects for education and the propensity score.

(i.e. only those cognitive abilities used at work are maintained better). An example of this is the finding that workers in sales, administration and education who continued participating in the workforce at an older age had a significantly slower decline in visual scanning compared to those who dropped out of the labour force. Future studies should investigate the level of visual scanning, verbal learning and delayed recall in the occupational setting in order to gain a better understanding of their association with cognitive decline in old age. Previous studies have investigated the level of mental demands (Dartigues et al., 1992a; Then et al., 2017) and job complexity (Andel et al., 2005; Smart et al., 2014), and observed differential effects with respect to the type of intellectual demands faced at work. An important indication from our study findings for public health is that decisions for optimal retirement ages should be occupation-specific as working longer should only come with a slower cognitive decline if the person is actively using cognitive resources. 
The cognitive tests used in this study assess memory in terms of verbal learning, and delayed recall and attention in terms of visual scanning. Verbal memory performance is the strongest predictor of dementia (Prado et al., 2019). In our study, working actively was associated with a poorer performance as well as a slower decline in an occupation-specific context. Especially domestic workers who worked actively had a significantly faster memory decline. Domestic workers might experience high strain in their job (instead of intellectual stimulation) so that working longer in later life accelerates decline of memory abilities (Agbenyikey et al., 2015). Visual scanning, on the other hand, involves selective attention (Eizenman et al., 2003), and performance in visual scanning typically decreases with age (Trick and Enns, 1998). Slowing the decline of visual scanning might signify a slowing of age-related cognitive decline. Our results from a population-based sample suggest that working actively in later life as a worker in sales, administration and education might have that effect.

In Mexico, the prevalence of dementia is around 6 per cent, and of those with dementia, 90 per cent had less than six years of education (Mejia-Arango and Gutierrez, 2011). Low levels of education, rural living conditions and low income (Miu et al., 2016), a result also of the economic crises in the 1980s and 1990s, led to the poorer health of older Mexican people (Cutler et al., 2002) that may subsequently increase the risk of cognitive impairment and dementia. With the lack of a comprehensive retirement system, many Mexicans may be forced to work in old age despite poor health. This, however, does not always help to maintain their cognitive functioning, as our results show. Hence, for many Mexicans, it means completing the same work tasks in later life and with declining cognitive abilities.

The strengths of our study are the representative population-based sample that included rural areas in Mexico as well as the longitudinal standardised observations. Nonetheless, our analysis comes with several limitations that are worth mentioning. First, we were unable to investigate cognitive function among study participants who required proxies as these respondents do not receive the CCCE. We also had to exclude from the analyses many participants with missing data. Excluded participants were more likely to be sick or have less education so that our sample may then exclude those in the population with poorest cognitive abilities. Conclusions drawn from the analysis cannot be generalised for population groups with low education and with more chronic health problems. Second, occupation is a difficult construct to measure as occupations may change throughout the lifecourse. Our analyses were based on the main job respondents worked and their current job, among those working during the study. Recall bias due to self-reports may have affected the results. Third, due to the long gap between the 2003 and 2012 waves of the MHAS, it was difficult to estimate a cubic decline in cognition over follow-up. Fourth, survival bias may have affected the results. Hence, we can only draw conclusions for those people who achieve a higher age. Fifth, we cannot exclude the possibility of reverse causation, particularly that participation in the labour force may be influenced by cognitive abilities. Sixth, occupational types do not provide specific information on job characteristics such as mental demands and stress, which could play a role, and we recommend that future studies explore these detailed occupational characteristics. Moreover, given the large number of 
statistical tests, there is an increased probability for incorrectly rejecting the null hypothesis. Finally, we cannot be sure that the cognitive tests we used were sensitive enough to capture the changes in cognition due to occupation and working status.

The decision to continue working in old age might not necessarily lead to beneficial effects for cognitive functioning in older people in Mexico as many Mexicans are employed in occupations that do not provide this benefit. Policy decisions should therefore focus on risk factors that drive dementia risk. Specific factors in the occupational context may determine this risk. Further studies are necessary to devote effort to this topic.

Supplementary material. The supplementary material for this article can be found at https://doi.org/10. $1017 / \mathrm{S} 0144686 \mathrm{X} 2100012 \mathrm{X}$

Acknowledgement. The findings of this study were presented at the GSA 2018 in Boston.

Author contributions.

FSR and JS made equal contributions to conceptualising the study, planning the analysis and interpreting the data. FSR conducted the data analysis, wrote the first and further drafts of the manuscript, and agreed to the final version of the manuscript. JS critically revised the content of the data analysis and any further versions of the manuscript, and agreed to the final version of the manuscript.

Financial support. This work was supported by the German Research Foundation (DFG) (FSR, grant number TH2137/3-1); Hans and Ilse Breuer Stiftung (FSR); and the National Institutes of Health (NIH) (JS, grant number K99AG058799 and R00 AG058799). The Mexican Health and Aging Study (MHAS) was funded by the NIH (grant number R01AG018016). The sponsors had no role in the design, methods, subject recruitment, data collections, analysis and preparation of the paper.

Conflict of interest. The authors declare no conflicts of interest.

Ethical standards. The Mexican Health and Aging Study (MHAS) study protocol was approved by the Institutional Review Board or Ethics Committee of the University of Texas Medical Branch, the Instituto Nacional de Estadística y Geografía (INEGI) in Mexico and the Instituto Nacional de Salud Pública (INSP) in Mexico. The study was conducted in accordance with the World Medical Association Declaration of Helsinki. Participants gave their written informed consent.

\section{References}

Agbenyikey W, Karasek R, Cifuentes M, Wolf PA, Seshadri S, Taylor JA, Beiser AS and Au R (2015) Job strain and cognitive decline: a prospective study of the Framingham Offspring cohort. International Journal of Occupational and Environmental Medicine 6, 79-94.

Aguilar-Navarro SG, Fuentes-Cantu A, Avila-Funes JA and Garcia-Mayo EJ (2007a) Validity and reliability of the screening questionnaire for geriatric depression used in the Mexican Health and Age Study. Salud Pública de México 49, 256-262.

Aguilar-Navarro SG, Reyes-Guerrero J and Borgues G (2007b) Cognitive impairment and alcohol and cigarette consumption in Mexican adults older than 65 years. Salud Pública de México 49, 467-474.

Andel R, Crowe M, Pedersen NL, Mortimer J, Crimmins E, Johansson B and Gatz M (2005) Complexity of work and risk of Alzheimer's disease: a population-based study of Swedish twins. Journals of Gerontology: Psychological Sciences and Social Sciences 60, P251-P258.

Anttila T, Helkala EL, Kivipelto M, Hallikainen M, Alhainen K, Heinonen H, Mannermaa A, Tuomilehto J, Soininen H and Nissinen A (2002) Midlife income, occupation, APOE status, and dementia: a population-based study. Neurology 59, 887-893.

Barnes-Farrell JL (2003) Beyond health and wealth: attitudinal and other influences on retirement decision-making. In Adams GA and Beehr TA (eds), Retirement: Reasons, Processes, and Results. New York, NY: Springer, pp. 159-187. 
Beck IR, Gagneux-Zurbriggen A, Berres M, Taylor KI and Monsch AU (2012) Comparison of verbal episodic memory measures: Consortium to Establish a Registry for Alzheimer's Disease-Neuropsychological Assessment Battery (CERAD-NAB) versus California Verbal Learning Test (CVLT). Archives of Clinical Neuropsychology 27, 510-519.

Belleville S, Fouquet C, Hudon C, Zomahoun HTV, Croteau J and Consortium for the Early Identification of Alzheimer's disease-Quebec (2017) Neuropsychological measures that predict progression from mild cognitive impairment to Alzheimer's type dementia in older adults: a systematic review and meta-analysis. Neuropsychology Review 27, 328-353.

Besamusca J, Tijdens K, Keune M and Steinmetz S (2015) Working women worldwide. Age effects in female labor force participation in 117 countries. World Development 74, 123-141.

Biondi-Zoccai G, Romagnoli E, Agostoni P, Capodanno D, Castagno D, D’Ascenzo F, Sangiorgi G and Modena MG (2011) Are propensity scores really superior to standard multivariable analysis? Contemporary Clinical Trials 32, 731-740.

Calvo E, Bertranou FM and Bertranou E (2010) Are old-age pension system reforms moving away from individual retirement accounts in Latin America? Journal of Social Policy 39, 223-234.

Carr DC, Willis R, Kail BL and Carstensen LL (2020) Alternative retirement paths and cognitive performance: exploring the role of preretirement job complexity. The Gerontologist 60, 460-471.

Cavuto S, Bravi F, Grassi M and Apolone G (2006) Propensity score for the analysis of observational data: an introduction and an illustrative example. Drug Development Research 67, 208-216.

Consejo Nacional de Población (2004) Envejecimiento de la Población de México: Reto del siglo XXI. Mexico, Mexico: Consejo Nacional de Población.

Cosío MEZ and Ferreiro J (1992) Cambios de fecundidad en México y políticas de población. Tlalpan, Mexico: El Colegio de Mexico and Fondo de Cultura Economica.

Cutler DM, Knaul F, Lozano R, Mendez O and Zurita B (2002) Financial crisis, health outcomes and ageing: Mexico in the 1980s and 1990s. Journal of Public Economics 84, 279-303.

Dartigues JF, Gagnon M, Letenneur L, Barberger-Gateau P, Commenges D, Evaldre M and Salamon R (1992a) Principal lifetime occupation and cognitive impairment in a French elderly cohort (Paquid). American Journal of Epidemiology 135, 981-988.

Dartigues J-F, Gagnon M, Mazaux J, Barberger-Gateau P, Commenges D, Letenneur L and Orgogozo J (1992b) Occupation during life and memory performance in nondemented French elderly community residents. Neurology 42, 1697-1701.

Eizenman M, Yu LH, Grupp L, Eizenman E, Ellenbogen M, Gemar M and Levitan RD (2003) A naturalistic visual scanning approach to assess selective attention in major depressive disorder. Psychiatric Research 118, 117-128.

Fang H, Johnson C, Chevalier N, Stopp C, Wiebe S, Wakschlag LS and Espy KA (2010) Using propensity score modeling to minimize the influence of confounding risks related to prenatal tobacco exposure. Nicotine \& Tobacco Research 12, 1211-1219.

Finkel D, Andel R, Gatz M and Pedersen NL (2009) The role of occupational complexity in trajectories of cognitive aging before and after retirement. Psychology and Aging 24, 563-573.

Fisher GG, Stachowski A, Infurna FJ, Faul JD, Grosch J and Tetrick LE (2014) Mental work demands, retirement, and longitudinal trajectories of cognitive functioning. Journal of Occupational Health Psychology 19, 231-242.

Gasparini L and Tornarolli L (2009) Labor informality in Latin America and the Caribbean: patterns and trends from household survey microdata. Revista Desarrollo y Sociedad 63, 13-80.

Glosser G, Wolfe N, Albert ML, Lavine L, Steele JC, Calne DB and Schoenberg BS (1993) Cross-Cultural Cognitive Examination-validation of a dementia screening instrument for neuroepidemiological research. Journal of the American Geriatrics Society 41, 931-939.

Glosser G, Wolfe N, Kliner-Krenzel L and Albert ML (1994) Cross-Cultural Cognitive Examination performance in patients with Parkinson's disease and Alzheimer's disease. Journal of Nervous and Mental Disease 182, 432-436.

Grotz C, Meillon C, Amieva H, Stern Y, Dartigues JF, Adam S and Letenneur L (2015) Why is later age at retirement beneficial for cognition? Results from a French population-based study. Journal of Nutrition, Health \& Aging 20, 514-519. 
Helmer C, Letenneur L, Rouch I, Richard-Harston S, Barberger-Gateau P, Fabrigoule C, Orgogozo J and Dartigues J (2001) Occupation during life and risk of dementia in French elderly community residents. Journal of Neurology, Neurosurgery \& Psychiatry 71, 303-309.

Hurd MD, Martorell P, Delavande A, Mullen KJ and Langa KM (2013) Monetary costs of dementia in the United States. New England Journal of Medicine 368, 1326-1334.

Instituto Nacional de Estadística y Geografía (2017) Resultados de la encuesta nacional de ocupación y empleo. Cifras durante el cuarto trimestre de 2016. Aguascalientes, Mexico: Instituto Nacional de Estadística y Geografía.

Jorm AF, Rodgers B, Henderson AS, Korten AE, Jacomb PA, Christensen H and Mackinnon A (1998) Occupation type as a predictor of cognitive decline and dementia in old age. Age and Ageing 27, 477483.

Langa KM, Chernew ME, Kabeto MU, Herzog AR, Ofstedal MB, Willis RJ, Wallace RB, Mucha LM, Straus WL and Fendrick AM (2001) National estimates of the quantity and cost of informal caregiving for the elderly with dementia. Journal of General Internal Medicine 16, 770-778.

Lupton MK, Stahl D, Archer N, Foy C, Poppe M, Lovestone S, Hollingworth P, Williams J, Owen MJ and Dowzell K (2010) Education, occupation and retirement age effects on the age of onset of Alzheimer's disease. International Journal of Geriatric Psychiatry 25, 30-36.

Mejia-Arango S and Gutierrez LM (2011) Prevalence and incidence rates of dementia and cognitive impairment on dementia in the Mexican population: data from the Mexican Health and Aging Study. Journal of Aging and Health 23, 1050-1074.

Miu J, Negin J, Salinas-Rodriguez A, Manrique-Espinoza B, Sosa-Ortiz AL, Cumming R and Kowal P (2016) Factors associated with cognitive function in older adults in Mexico. Global Health Action 9, 30747.

Prado CE, Watt S, Treeby MS and Crowe SF (2019) Performance on neuropsychological assessment and progression to dementia: a meta-analysis. Psychology and Aging 34, 954-977.

Qiu C, Karp A, von Strauss E, Winblad B, Fratiglioni L and Bellander T (2003) Lifetime principal occupation and risk of Alzheimer's disease in the Kungsholmen project. American Journal of Industrial Medicine 43, 204-211.

Radloff LS (2016) The CES-D scale. Applied Psychological Measurement 1, 385-401.

Saenz JL, Downer B, Garcia MA and Wong R (2017) Cognition and context: rural-urban differences in cognitive aging among older Mexican adults. Journal of Aging and Health 30, 965-986.

Saenz JL, Wong R and Ailshire JA (2018) Indoor air pollution and cognitive function among older Mexican adults. Journal of Epidemiology and Community Health 72, 21-26.

Salthouse TA (2006) Mental exercise and mental aging evaluating the validity of the 'use it or lose it' hypothesis. Perspectives on Psychological Science 1, 68-87.

Salthouse TA (2009) When does age-related cognitive decline begin? Neurobiology of Aging 30, 507-514.

Smart EL, Gow AJ and Deary IJ (2014) Occupational complexity and lifetime cognitive abilities. Neurology 83, 2285-2291.

Staff RT, Hogan MJ, Williams DS and Whalley LJ (2018) Intellectual engagement and cognitive ability in later life (the 'use it or lose it' conjecture): longitudinal, prospective study. BMJ 363, k4925.

Swaab DF (1991) Brain aging and Alzheimer's disease, 'wear and tear' versus 'use it or lose it'. Neurobiology of Aging 12, 317-324.

Then FS, Luck T, Luppa M, Thinschmidt M, Deckert S, Nieuwenhuijsen K, Seidler A and Riedel-Heller SG (2014) Systematic review of the effect of the psychosocial working environment on cognition and dementia. Occupational and Environmental Medicine 71, 358-365.

Then FS, Luck T, Heser K, Ernst A, Posselt T, Wiese B, Mamone S, Brettschneider C, Konig HH, Weyerer S, Werle J, Mosch E, Bickel H, Fuchs A, Pentzek M, Maier W, Scherer M, Wagner M and Riedel-Heller SG (2017) Which types of mental work demands may be associated with reduced risk of dementia? Alzheimers \& Dementia 13, 431-440.

Trick LM and Enns JT (1998) Lifespan changes in attention: the visual search task. Cognitive Development 13, 369-386.

Tuesta D (2017) Retirement and labour markets under the context of pension reform in Latin America. Economic and Political Studies 5, 475-500. 
Wolfe N, Imai Y, Otani C, Nagatani H, Hasegawa K, Sugimoto K, Tanaka Y, Kuroda Y, Glosser G and Albert ML (1992) Criterion validity of the cross-cultural cognitive examination in Japan. Journal of Gerontology 47, P289-P291.

Wong R and Palloni A (2009) Aging in Mexico and Latin America. In Uhlenberg P (ed.), International Handbook of Population Aging. New York, NY: Springer, pp. 231-252.

Wong R, Michaels-Obregon A and Palloni A (2015a) Cohort profile: the Mexican Health and Aging Study (MHAS). International Journal of Epidemiology 46, e2.

Wong R, Michaels-Obregon A, Palloni A, Gutierrez-Robledo LM, Gonzalez-Gonzalez C, Lopez-Ortega M, Tellez-Rojo MM and Mendoza-Alvarado LR (2017) Progression of aging in Mexico: the Mexican Health and Aging Study (MHAS) 2012. Salud Pública de México 57, S79-S89.

World Bank (2017) Employment in Agriculture. International Labour Organization, Key Indicators of the Labour Market Database. Washington, DC: World Bank.

World Health Organization (2016) Mental Health and Older Adults. Geneva: World Health Organization.

Zeki Al Hazzouri A, Haan MN, Galea S and Aiello AE (2011) Life-course exposure to early socioeconomic environment, education in relation to late-life cognitive function among older Mexicans and Mexican Americans. Journal of Aging and Health 23, 1027-1049.

Cite this article: Rodriguez FS, Saenz J (2022). Working in old age in Mexico: implications for cognitive functioning. Ageing \& Society 42, 2489-2509. https://doi.org/10.1017/S0144686X2100012X 